\title{
Reoperations after tricuspid valve repair
}

José M. Bernal, MD, ${ }^{a}$ Dieter Morales, MD, ${ }^{a}$ Carmen Revuelta, MD, ${ }^{a}$ Javier Llorca, MD, ${ }^{\mathrm{b}}$ Jesús Gutiérrez-Morlote, MD, and José M. Revuelta, MD

From the Department of Cardiovascular Surgery, Hospital Universitario Valdecilla, ${ }^{a}$ and Division of Preventive Medicine and Public Health, ${ }^{\mathrm{b}}$ Universidad de Cantabria, Santander, Spain.

Received for publication Nov 2, 2004; revisions received Dec 23, 2004; accepted for publication Dec 28, 2004.

Address for reprints: José M. Bernal, MD, Department of Cardiovascular Surgery, Hospital Universitario Valdecilla, E-39008 Santander, Spain (E-mail: ccabmj@humv.es).

J Thorac Cardiovasc Surg 2005;130:498-503

$0022-5223 / \$ 30.00$

Copyright $\odot 2005$ by The American Association for Thoracic Surgery

doi:10.1016/j.jtcvs.2004.12.044
Objective: The objective was to analyze the short- and long-term results of patients with previous tricuspid valve repair who had valve dysfunction and required cardiac reoperations.

Methods: Between 1976 and 2002, 74 patients with a mean age of $53.8 \pm 12.2$ years underwent valve reoperations for dysfunction of previous tricuspid valve repair. Mitral and tricuspid lesions were diagnosed in 40 patients (54\%), triple valve disease (mitral, aortic, tricuspid) was diagnosed in 26 patients $(35.1 \%)$, isolated tricuspid disease was diagnosed in 6 patients $(8.1 \%)$, and aortic and tricuspid lesions were diagnosed in 2 patients (2.7\%). Reoperations included tricuspid valve replacement in 43 patients $(58.1 \%)$ and a new tricuspid valve repair procedure in the remaining 31 patients $(41.9 \%)$.

Results: Hospital mortality (30-day or within first admission) was $35.1 \%(\mathrm{n}=26)$. In the multivariate analysis, risk factors for hospital mortality included body mass index less than $20 \mathrm{~kg} / \mathrm{m}^{2}$ and greater than $24 \mathrm{~kg} / \mathrm{m}^{2}$, triple valve disease, use of intra-aortic balloon counterpulsation, and presence of postoperative complications. The follow-up was complete in $100 \%$ of patients, with a mean follow-up of 14.2 years (range 4 months to 26 years). The late mortality was $40.5 \%(\mathrm{n}=30)$. Predictors of late mortality were body mass index less than $20 \mathrm{~kg} / \mathrm{m}^{2}$, cardiac surgery before 1991, and development of dysfunction early after tricuspid valve repair. At the follow-up closing date, 19 patients are alive $(25.7 \%)$. The actuarial survival was $11.8 \% \pm 4.9 \%$ at 26 years.

Conclusions: Patients with failure of a tricuspid valve repair procedure requiring reoperation have a poor prognosis with a high mortality rate both in-hospital and in the long-term.

$\mathrm{T}$ he current health care level in Spain is comparable to that of other advanced industrial countries, but the eradication of rheumatic fever is a recent occurrence. Therefore, left-sided valvular lesions and dysfunctional tricuspid valves still have been diagnosed and treated with modern technologies in a substantial number of patients. ${ }^{1,2}$ It is well known that tricuspid disease associated with mitral or mitro-aortic valvular lesions may result in poor early and late functional results. ${ }^{3,4}$ On the other hand, mortality after prosthetic valve replacement is higher than after tricuspid valve annuloplasty. ${ }^{5,6}$ Little is known about the natural history of patients with polyvalvular disease and tricuspid involvement undergoing tricuspid valve repair (annuloplasty and/or commissurotomy) who require reoperation for significant tricuspid dysfunction. On the other hand, patients undergoing reoperation for tricuspid valve dysfunction have scarcely been analyzed, and data of these cases are mostly included in the general series of reoperations for valvular surgery. ${ }^{7-9}$ This finding prompted us to review our experience with reoperations after tricuspid valve repair and to determine those factors that influence early and late results. 


\section{Methods}

Between 1976 and 2002, 74 patients aged $53.77 \pm 12.19$ years (range 23-74 years) underwent reoperation for tricuspid valve dysfunction of a previous tricuspid valve repair. There were 11 male patients and 63 female patients. Forty-six patients underwent reoperation between 1976 and 1990, and the remaining 28 patients underwent reoperation between 1991 and 2002. The reason to divide the study period into 2 groups was related to the observation of statistically significant differences in late mortality between patients who underwent an operation before 1991 and after 1991. The mean interval between reoperation and the first tricuspid valve repair was $8.2 \pm 4.35$ years. Forty-two patients $(56.8 \%)$ were in New York Heart Association (NYHA) functional class III, and 32 patients $(43.2 \%)$ were in NYHA class IV. Main preoperative risk factors included pulmonary hypertension in 62 patients $(83.8 \%)$, history of thromboembolic disease in 15 patients (20.3\%), and renal insufficiency in 4 patients $(5.4 \%)$. On the other hand, physical signs of congestive heart failure (ascites, hepatomegaly, peripheral edemas, and/or distention of the jugular veins) were moderate in 28 patients $(37.8 \%)$ and severe in 12 patients (15.4\%).

All patients had undergone the operation with extracorporeal circulation, and tricuspid valve operation was performed after surgical treatment of the mitral or aortic valve. Previous valve operations included annuloplasty with a Duran flexible ring in 27 patients $(36.5 \%)$, De Vega's annuloplasty in 8 patients $(10.8 \%)$, segmental annuloplasty in 10 patients $(13.5 \%)$, annuloplasty with a Duran flexible ring and tricuspid commissurotomy in 24 patients $(34.5 \%)$, and other repair procedures in 5 patients $(6.8 \%)$. Patients with mitral lesions $(\mathrm{n}=74)$ underwent mitral valve repair $(\mathrm{n}=28$, $37.8 \%)$ or prosthetic valve replacement $(\mathrm{n}=46,62.2 \%)$. Patients with aortic lesions $(\mathrm{n}=24)$ underwent aortic valve repair $(\mathrm{n}=6$, $8.1 \%)$ or prosthetic valve replacement $(n=8,24.3 \%)$. The cause was rheumatic heart disease in 66 patients $(89.2 \%)$ and degenerative disease in 8 patients $(10.8 \%)$. There were 47 patients $(63.5 \%)$ with organic tricuspid lesions and 27 patients (36.5\%) with functional tricuspid disease. Sixty-four patients had complete arrhythmia caused by atrial fibrillation, and 10 patients were in sinus rhythm.

All patients were investigated preoperatively by means of echocardiography of different modes according to the year of the study, in association with hemodynamic studies in 35 patients $(47.3 \%)$, particularly in those undergoing operation during the initial years of the study. Tricuspid regurgitation was graded on a scale of $1+$ to $4+$. Hemodynamic data are given in Table 1.

After completion of echocardiographic and hemodynamic studies, mitral and tricuspid lesions were diagnosed in 40 patients (54.1\%), triple valve disease was diagnosed in 26 patients $(35.1 \%)$, isolated tricuspid disease was diagnosed in 6 patients $(2.7 \%)$, and aortic and tricuspid lesions were diagnosed in 2 patients $(2.7 \%)$. Tricuspid insufficiency was considered to be present in 60 patients (81.1\%), a double tricuspid lesion (stenosis and insufficiency) was present in 9 patients $(12.2 \%)$, and pure tricuspid stenosis was present in the remaining 5 patients $(6.8 \%)$. Grades of tricuspid regurgitation were $3+$ in 16 patients and $4+$ in 44 patients. Reoperation was indicated because of progression of valve disease in 25 patients $(33.8 \%)$, early failure of tricuspid valve repair in 11 patients (14.9\%), prosthetic dysfunction in 24 patients (32.5),
TABLE 1. Results of preoperative hemodynamic studies

\begin{tabular}{lc}
\hline Parameter & Mean \pm SD (range) \\
\hline Pulmonary capillary pressure, mm Hg & $23.75 \pm 6.46(11-40)$ \\
Pulmonary artery systolic pressure, & $56.40 \pm 18.41(13-100)$ \\
$\quad \mathrm{mm} \mathrm{Hg}$ & \\
Cardiac index, $\mathrm{L} \cdot \mathrm{min} \cdot \mathrm{m}^{2}$ & $2.34 \pm 0.66(1.37-4.3)$ \\
Mitral valve gradient, $\mathrm{mm} \mathrm{Hg}$ & $14.72 \pm 7.35(2-38)$ \\
Tricuspid valve gradient, $\mathrm{mm} \mathrm{Hg}$ & $6.79 \pm 3.93(3-18)$ \\
Aortic valve gradient, mm Hg & $30.92 \pm 16.05(6-58)$ \\
Left ventricular ejection fraction, $\%$ & $56.07 \pm 12.51(22-88)$ \\
\hline
\end{tabular}

prosthetic endocarditis in 4 patients (5.4\%), and dehiscence of a prosthesis in 10 patients $(13.5 \%)$.

Reoperations were performed through a median sternotomy with extracorporeal circulation. Forty-three patients $(58.1 \%)$ underwent prosthetic tricuspid valve replacement (mechanical prosthesis in 18 and bioprosthesis in 25). Repair of the tricuspid valve was performed in 31 patients. Types of repairs were as follows: flexible ring annuloplasty in 6 patients, a new De Vega's or segmental annuloplasty on a previous suture annuloplasty in 10 patients, resuture of the flexible ring in 7 patients, removal of the flexible ring because of stenosis in 3 patients, Wooler-Reed annuloplasty at the posterior leaflet in 2 patients, closure of the anteroposterior commissurotomy in 1 patient (this patient had a previous commissurotomy), transverse section of a stenotic flexible ring in 1 patient, and suture of the anteroseptal commissure in 1 patient (this patient had a previous commissurotomy).

\section{Follow-up}

The follow-up data for this study were procured in a 5-month period (November 2003 to March 2004). The patients were followed through visits in our outpatient clinic $(n=29)$, direct contact at home $(\mathrm{n}=10)$, or direct contact with their cardiologists $(n=6)$. When follow-up was not possible, information on vital status (alive or death) was obtained through the Social Security database $(\mathrm{n}=4)$. Follow-up was $100 \%$ complete, with a mean follow-up of 14.2 years (range 4 months to 26 years).

\section{Statistical Methods}

The Patient Analysis and Tracking System database, version 06.02.03 (Dendrite Clinical System, Inc, Portland, Ore) was used. Values are expressed as mean $\pm \mathrm{SD}$. The Student $t$ test was used for the comparison of quantitative variables. Factors influencing intrahospital mortality (ie, death before 30 days after surgery) were analyzed using multiple logistic regression; its results are expressed as odds ratios. Survival curves were obtained by actuarial method. Proportional hazards regression (Cox) was used to study the influence of covariates on mortality and reoperation; we present its results as hazard ratios. Multivariate analysis was performed with the Stata Intercooled, release 6 (Stata Corporation, College Station, Tex) computer program.

\section{Results}

\section{Postoperative Complications}

Severe postoperative complications developed in 48 patients $(64.9 \%)$. Thirteen patients $(17.6 \%)$ required an early 
TABLE 2. Predictors of mortality in the multivariate analysis

\begin{tabular}{|c|c|c|}
\hline & & $P$ value \\
\hline Hospital mortality* & Odds ratio $(95 \% \mathrm{Cl})$ & \\
\hline $\mathrm{BMI}>24 \mathrm{~kg} / \mathrm{m}^{2}$ & $4.91(1.11-21.60)$ & .035 \\
\hline $\mathrm{BMI}<20 \mathrm{~kg} / \mathrm{m}^{2}$ & $5.22(0.75-36.50)$ & .096 \\
\hline Balloon counterpulsation & $5.91(1.32-26.47)$ & .020 \\
\hline $\begin{array}{l}\text { Severe postoperative } \\
\text { complications }\end{array}$ & $10.24(1.63-64.30)$ & .013 \\
\hline Triple valve disease & $2.90(0.76-11.02)$ & .118 \\
\hline Late mortality† & Hazard ratio $(95 \%$ Cl) & \\
\hline Operation before 1991 & $9.24(2.12-19.42)$ & .0062 \\
\hline $\mathrm{BMI}<20 \mathrm{~kg} / \mathrm{m}^{2}$ & $4.39(1.19-23.45)$ & .082 \\
\hline Indication of reoperation & $6.89(3.90-26.76)$ & .034 \\
\hline Overall mortality $\ddagger$ & Hazard ratio $(95 \%$ CI $)$ & \\
\hline Operation before 1991 & $11.12(4.56-30.98)$ & .0012 \\
\hline $\mathrm{BMI}<20 \mathrm{~kg} / \mathrm{m}^{2}$ & 4.89 (2.17-10.89) & .078 \\
\hline Balloon counterpulsation & 5.38 (2.34-19.89) & .023 \\
\hline $\begin{array}{l}\text { Severe postoperative } \\
\text { complications }\end{array}$ & $12.12(4.12-45.09)$ & .093 \\
\hline Indication of reoperation & $3.65(0.68-8.46)$ & .052 \\
\hline
\end{tabular}

BMI, Body mass index; $C l$, confidence interval. *Pseudo $\mathrm{R}^{2}=0.3352$. $\dagger$ Pseudo $R^{2}=0.3212$. $¥$ Pseudo $R^{2}=0.3491$.

reoperation because of postoperative hemorrhage in 6 , sternal dehiscence in 4 , mediastinitis in 2 , and epicardial pacemaker implantation in 1. Infection of the sternotomy occurred in 4 patients, and another patient presented with a catheter-related sepsis. Six patients $(8.1 \%)$ had an ischemic stroke. Four of these patients were discharged without neurologic deficit, and 2 patients had functional sequelae. Respiratory complications developed in 10 patients $(13.5 \%)$; these patients required assisted ventilation for more than 5 days. Renal insufficiency was diagnosed in 20 patients $(27 \%), 6$ of whom were treated with dialysis.

\section{Hospital Mortality}

The hospital mortality (30-day or within first admission) was $33.8 \%$ (25 patients).

Causes of death were cardiac in $64 \%$ of cases, infection in $8 \%$, neurologic in $8 \%$, renal failure in $8 \%$, and bleeding in $12 \%$. Univariate analysis identified the grade of tricuspid regurgitation, indication of reoperation, use of balloon counterpulsation, and severe postoperative complications as significant predictors of hospital mortality. The mean grade of tricuspid regurgitation was $3.60 \pm 0.63$ in deceased patients and $3.36 \pm 0.48$ in survivors $(P=.002)$. The mortality was $16.7 \%$ in patients in whom the reason of reoperation was failure of a bioprosthesis and $42 \%$ for all other indications $(P=.033)$. The use of balloon counterpulsation had a significantly higher mortality $(73.3 \%$ vs $23.7 \%, P<.005)$ as well as the presence of severe postoperative complications $(45.8 \%$ vs $11.1 \%, P<.005)$.
$\%$ survivors

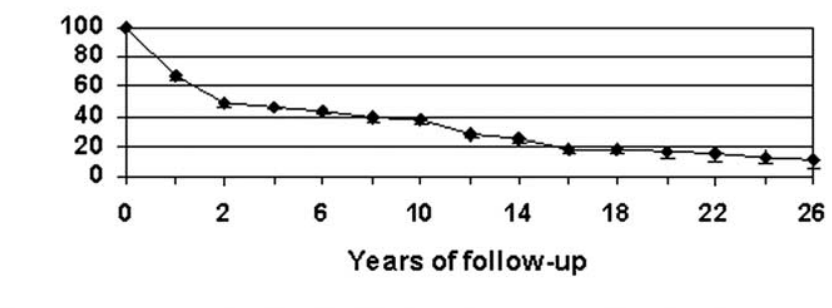

Patients at risk: $\quad \begin{array}{lllllllllllll}49 & 32 & 29 & 23 & 20 & 16 & 11 & 10 & 7 & 6 & 5 & 4 & 1\end{array}$

Figure 1. Actuarial survival curve after reoperations for failure of previous tricuspid valve repair.

With the multiple regression model, body mass index (BMI) less than $20 \mathrm{~kg} / \mathrm{m}^{2}$ and greater than $24 \mathrm{~kg} / \mathrm{m}^{2}$, triple valve disease, use of intra-aortic balloon counterpulsation, and severe postoperative complications were statistically significant risk factors for hospital mortality (Table 2). The area under the receiver operating characteristics curve was 0.8540 .

\section{Late Deaths}

There were 30 late deaths among 49 perioperative survivors (late mortality $40.5 \%$ ). Causes of death were successive reoperations in 5 patients, valve related in 9 patients, endstage heart failure in 11 patients, and unknown in 5 patients. The actuarial survival was $11.8 \% \pm 4.9 \%$ at 26 years (Figure 1). In the univariate analysis, operation before 1991 and indication of reoperation were significant predictors of late death. Mortality was $75 \%$ in patients who underwent operation before 1991 and 35\% in those who underwent operation after $1991(P=.008)$. Mortality was $100 \%$ in operations performed for early failure of tricuspid valve repair compared with $70.6 \%$ in operations performed for failure of a bioprosthesis and $46.2 \%$ in operations performed for progression of the disease $(P=.049)$. There were no significant differences between patients with and without pulmonary hypertension, that is, preoperative values of pulmonary artery systolic pressure had no effect on either early or late clinical outcome.

In the multivariate analysis, operation performed before 1991, BMI less than $20 \mathrm{~kg} / \mathrm{m}^{2}$, and early failure of valve repair as the indication for reoperation were significant risk factors for late death (Table 2).

\section{Overall Mortality}

Overall mortality was $74.3 \%$, with 19 survivors (25.7\%). Risk factors for death in patients undergoing tricuspid valve reoperation included operation performed before 1991 ( $86.7 \%$ vs $55.2 \%, P<.005$ ); use of an intra-aortic balloon counterpulsation $(100 \%$ vs $67.8 \%, P=.011)$; early failure 
of tricuspid valve repair compared with other causes $(100 \%$ vs $70.3 \%, P=.047)$; and severe postoperative complications $(85.4 \%$ vs $55.6 \%, P<.005)$. In the multivariate analysis, risk factors for overall mortality were operation performed before 1991, BMI less than $20 \mathrm{~kg} / \mathrm{m}^{2}$, use of balloon counterpulsation, and early failure of valve repair (Table 2). Hospital mortality and late mortality were $41.8 \%$ and $39.5 \%$, respectively, for patients undergoing prosthetic valve replacement. The corresponding figures for patients undergoing a new tricuspid valve repair were $22.6 \%$ and $41.9 \%$, respectively.

\section{Reoperations}

Of the 49 patients who survived the reoperation, 13 required a third operation because of severe tricuspid insufficiency associated with failure of tricuspid valve repair $(n=1)$; mitral and tricuspid dysfunction $(\mathrm{n}=1)$; mitral, aortic, and tricuspid dysfunction $(\mathrm{n}=2)$; isolated mitral dysfunction $(\mathrm{n}=4)$; isolated aortic dysfunction $(\mathrm{n}=1)$; and mitroaortic dysfunction $(n=4)$. Indications of surgery included dysfunction of mitral and/or aortic bioprosthesis in 7 cases, prosthetic endocarditis in 1 case, and dehiscence of a prosthesis in 4 cases. In the 4 patients with a new tricuspid disease, a bioprosthesis was inserted in all of them.

Three patients $(23.1 \%)$ died at reoperation, and 10 patients $(76.9 \%)$ were discharged from the hospital. Six of these 10 patients underwent reoperation, 2 of whom died $(33.3 \%)$.

At the follow-up closing date, 15 of the 19 survivors were in NYHA functional class I or II (78.9\%), 3 survivors were in class III (15.8\%), and 1 survivor was in class IV (5.3\%). During the follow-up, 3 thromboembolic episodes were recorded, 5 patients had hemorrhagic episodes related to anticoagulation, and 1 patient had aortic prosthesisrelated endocarditis. The actuarial curve free from valverelated complications was $9.6 \% \pm 4.3 \%$ at 26 years (Figure 2).

\section{Discussion}

Rheumatic disease has been the most common cause of tricuspid valve lesions in the past. In developed countries, eradication of rheumatic disease was followed by a decrease in the incidence of tricuspid valve lesions, with functional regurgitation remaining as the most frequent cause. Clinical and surgical management of tricuspid valve disease have evolved from conservative approaches, that is, spontaneous regression after correction of left-sided lesions, to a more interventionist care. At present, it is well known that tricuspid regurgitation grades $3+$ and $4+$ that are not surgically corrected or that reappear after operation are prognostic factors of poor long-term outcome. ${ }^{10,11}$ On the other hand, decisions concerning surgical treatment have also changed from digital examination of the valve at operation to modern preoperative diagnostic techniques of Doppler echocardiog-
$\%$ free from valve-related complications

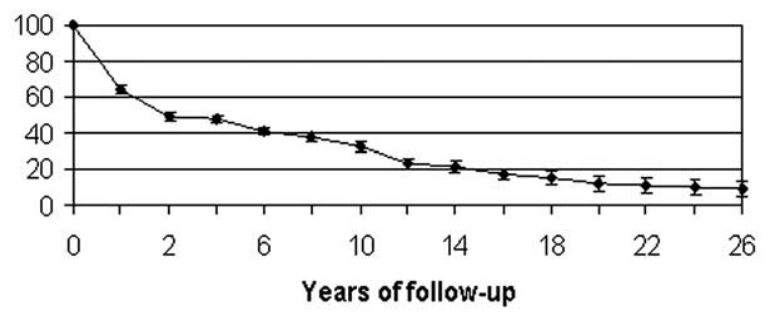

Patients at risk: $\quad \begin{array}{lllllllllllll}44 & 30 & 27 & 22 & 16 & 10 & 9 & 7 & 6 & 5 & 4 & 2 & 1\end{array}$

Figure 2. Actuarial curve free from valve-related complications after reoperations for failure of previous tricuspid valve repair.

raphy. In our country, the eradication of rheumatic fever occurred later than in other industrialized countries, and for this reason, tricuspid valve lesions of rheumatic origin have been frequently seen in the recent past. Different studies performed in the 1970s and 1980s have established the clinical and hemodynamic criteria for surgical treatment of left-sided valvular lesions. ${ }^{12,13}$ More recently, Doppler echocardiography has been used to assess the severity of right-sided valvular lesions and to establish the indication of tricuspid vale repair based exclusively on echocardiographic data. ${ }^{14}$

In our overall experience (1974-2002), 1080 patients underwent 1178 surgical procedures on the tricuspid valve, which included prosthetic valve replacement in 125 cases $(10.6 \%)$ and a valve repair technique in the remaining 1053 cases $(89.4 \%)$. The majority of survivors of tricuspid valve repair operations have an updated follow-up, some of them included in previous studies, ${ }^{1,2}$ and are referred to our center when a reoperation is necessary. An outstanding finding of the present study is that tricuspid valve repair can be considered a curative procedure because in more than 25 years of experience, repair operations of the tricuspid valve failed in only $7 \%$ of the patients $(n=74)$. Probably, no other surgical valvular procedure shows this stability. This observation has also been reported by other authors. ${ }^{15}$ In agreement with an extensive review recently published by McCarthy and associates, ${ }^{16}$ residual tricuspid regurgitation grades $3+$ or $4+$ may even be acceptably tolerated by patients; on the other hand, a reoperation of the tricuspid valve is sometimes not indicated because of the high risk of poor results. In the present series of 74 patients, failure of tricuspid valve repair developed because of intrinsic dysfunction of the valve $(n=6)$ and reappearance of left-sided disease $(n=68)$; these accounted for $0.6 \%$ and $6.4 \%$ of all cases of tricuspid valve repair. Therefore, in defense of De Vega's and other suture annuloplasties ${ }^{17,18}$ it should be mentioned that an intrinsic failure of this technique is rare. 
Recently, Carrier and associates ${ }^{19}$ reported 25 years of experience with repair of tricuspid insufficiency, with a mean freedom rate from tricuspid repair failure of $95 \% \pm$ $3 \%, 93 \% \pm 3 \%$, and $72 \% \pm 8 \%$ at 5,10 , and 15 years, respectively, after the De Vega semicircular annuloplasty.

It is well known that coexistence of a tricuspid valve lesion with a mitral or mitro-aortic valvular disease has a worse prognosis with an increased hospital mortality and, particularly, a poor long-term outcome. ${ }^{2,20-22}$ In the study of Mullany and associates, ${ }^{3}$ repair of tricuspid valve insufficiency in patients undergoing double (aortic and mitral) valve replacement was associated with an actuarial survival of $15 \%$ at 27 years, which is consistent with data reported by others. ${ }^{4,20,21}$ In our experience, the actuarial survival after tricuspid valve repair is $50.5 \%$ at 12 years. ${ }^{2}$ In agreement with other studies, ${ }^{9,15}$ dysfunction after tricuspid valve repair requiring reoperation was associated with a high hospital mortality (33.8\%) (combination of polyvalvular heart disease and reoperation). In our experience, hospital mortality after cardiac valve reoperations is greater than early mortality after native valve surgery. ${ }^{23}$ A multivariate Cox regression analysis for overall mortality revealed that obesity $\left(\right.$ BMI $\left.>24 \mathrm{~kg} / \mathrm{m}^{2}\right)$, cachexia $\left(\right.$ BMI $<20 \mathrm{~kg} / \mathrm{m}^{2}$ ), grade of tricuspid regurgitation, use of balloon counterpulsation, and severe postoperative complications were significantly associated with fatal outcome.

Late mortality was also high. Thirty patients died during the 26-year follow-up period ( $40.5 \%$ of the initial series), with a linear incidence of $2.1 \%$ patients per year and an actuarial survival of $11.8 \% \pm 4.9 \%$ at 26 years. These low survival figures have also been reported by other authors, such as a $15 \%$ survival at 27 years in the study of Mullany and associates, ${ }^{3}$ a $25 \%$ survival at 15 years in the study of McGrath and associates, ${ }^{4}$ or a $44 \%$ survival at 12 years in the study of Kay and associates. ${ }^{22}$ In accordance with the poor prognosis, the actuarial curve free from valve-related complications was $9.6 \% \pm 4.3 \%$ at 26 years, that is, in approximately one third of a century there are no patients with dysfunction of tricuspid valve repair requiring a reoperation who are free from valve-related problems. Of the overall series of 74 patients, only 19 patients $(25.7 \%)$ survived. End-stage heart failure was the most frequent cause of late death. This observation together with other findings indicates that an associated right ventricular dysfunction and pulmonary hypertension are probably the causes of tricuspid regurgitation and that this rightsided disease is responsible for the poor clinical results obtained. In addition, reoperations performed before 1991 showed an increased risk of late and overall mortality compared with operations after 1991. This is an expected finding related to general improvement of anesthetic and surgical techniques.
In conclusion, tricuspid vale repair is a long-term stable procedure; however, valve dysfunction requiring reoperation is associated with a high early and late mortality.

We thank Marta Pulido, MD, for editing the manuscript and for editorial assistance.

\section{References}

1. Duran CM, Pomar JL, Colman T, Figueroa A, Revuelta JM, Ubago JL. Is tricuspid valve repair necessary? J Thorac Cardiovasc Surg. 1980; 80:849-60.

2. Bernal JM, Gutiérrez-Morlote J, Llorca J, San Jose JM, Morales D, Revuelta JM. Tricuspid valve repair: an old disease, a modern experience. Ann Thorac Surg. 2004;78:2069-75.

3. Mullany CJ, Gersh BJ, Orszulak TA, Schaff HV, Puga FJ, Ilstrup DM, et al. Repair of tricuspid valve insufficiency in patients undergoing double (aortic and mitral) valve replacement. Perioperative mortality and long-term (1 to 20 years) follow-up in 109 patients. J Thorac Cardiovasc Surg. 1987;94:740-8.

4. McGrath LB, Gonzalez-Lavin L, Bailey BM, Grunkemeier GL, Fernandez J, Laub GW. Tricuspid valve operations in 530 patients. Twenty-five-year assessment of early and late phase events. J Thorac Cardiovasc Surg. 1990;99:124-33.

5. McGrath LB, Chen C, Bailey BM, Fernandez J, Laub GW, Adkins MS. Early and late phase events following bioprosthetic tricuspid valve replacement. J Card Surg. 1992;7:245-53.

6. Poveda JJ, Bernal JM, Matorras P, Hernando JP, Oliva MJ, Ochoteco A, et al. Tricuspid valve replacement in rheumatic disease: preoperative predictors of hospital mortality. J Heart Valve Dis. 1996;5:26-30.

7. Lytle BW, Cosgrove DM, Taylor PC, Gill CC, Goormastic M, Golding LR, et al. Reoperations for valve surgery: perioperative mortality and determinants of risk for 1,000 patients, 1958-1984. Ann Thorac Surg. 1986;42:632-43.

8. Jones JM, O'kane H, Gladstone DJ, Sarsam MA, Campalani G, MacGowan SW, et al. Repeat heart valve surgery: risk factors for operative mortality. J Thorac Cardiovasc Surg. 2001;122:913-8.

9. Hornick P, Harris PA, Taylor KM. Tricuspid valve replacement subsequent to previous open heart surgery. J Heart Valve Dis. 1996;5: $20-5$.

10. Kirali K, Omeoglu SN, Uzun K, Erentug V, Bozbuga N, Eren E, et al. Evolution of repaired and non-repaired tricuspid regurgitation in rheumatic mitral valve surgery without severe pulmonary hypertension. Asian Cardiovasc Thorac Ann. 2004;12:239-45.

11. Matsuyama K, Matsumoto M, Sugita T, Nishizawa J, Tokuda Y, Matsuo T. Predictors of residual tricuspid regurgitation after mitral valve surgery. Ann Thorac Surg. 2003;75:1826-8.

12. Ubago JL, Figueroa A, Ochoteco A, Colman T, Duran RM, Duran CG. Análisis of the amount of tricuspid valve anular dilatation required to produce functional tricuspid regurgitation. Am J Cardiol. 1983;52: $155-8$.

13. Ubago JL, Figueroa A, Ochoteco A, Colman T, Duran RM, Duran CG. Hemodynamic diagnosis of organic disease in the tricuspid valve. Rev Esp Cardiol. 1980;33:5155-23.

14. Gonzalez-Vilchez F, Zarauza J, Vazquez de Prada JA, Martin Duran R, Ruano J, Delgado C, et al. Assessment of tricuspid regurgitation by Doppler color flow imaging: angiographic correlation. Int J Cardiol. 1994;44:275-83.

15. Donzeau-Gouge P, Villard A, Olivier M, Guibourg P, d'Allaines C, Blondeau $\mathrm{P}$, et al. Tricuspid reoperation in the surgery of rheumatic valve diseases. Apropos of 24 cases. Arch Mal Coeur Vaiss. 1984;77: 255-61.

16. McCarthy PM, Bhudia SK, Rajeswaran J, Hoercher KJ, Lytle BW, Cosgrove DM, et al. Tricuspid valve repair: durability and risk factors for failure. J Thorac Cardiovasc Surg. 2004;127:674-85.

17. De Vega NG. Selective, adjustable and permanent annuloplasty. An original technique for the treatment of tricuspid insufficiency. Rev Esp Cardiol. 1972;25:555-6.

18. Revuelta JM, Garcia Rinaldi R. Segmental tricuspid annuloplasty: a new technique. J Thorac Cardiovasc Surg. 1989;97:799-801. 
19. Carrier M, Pellerin M, Guertin MC, Bouchard D, Hebert Y, Perrault LP, et al. Twenty-five years' clinical experience with repair of tricuspid insufficiency. J Heart Valve Dis. 2004;13:952-6.

20. Czer LS, Maurer G, Bolger A, DeRobertis M, Kleinman J, Gray RJ, et al. Tricuspid valve repair. Operative and follow-up evaluation by Doppler color flow mapping. J Thorac Cardiovasc Surg. 1989;98:10111.

21. Carrier M, Pellerin M, Bouchard D, Perrault LP, Cartier R,
Hebert Y, et al. Long-term results with triple valve surgery. Ann Thorac Surg. 2002;73:44-7.

22. Kay GL, Morita S, Mendez M, Zubiate P, Kay JH. Tricuspid regurgitation associated with mitral valve disease: repair and replacement. Ann Thorac Surg. 1989;48:S93-5.

23. Echevarria JR, Bernal JM, Rabasa JM, Morales D, Revilla Y, Revuelta JM. Reoperation for bioprosthetic valve dysfunction. A decade of clinical experience. Eur J Cardiothorac Surg. 1991;5:523-7. 